\title{
ANALISIS FAKTOR PEMILIHAN TEMPAT BERSALIN DI RUMAH SAKIT PADA IBU HAMIL
}

\author{
Gita Sekar Prihanti ${ }^{1}$, Ekky Dwi Rahmawan ${ }^{2}$, Lusiana Kusuma Wardhani ${ }^{2}$, Juanda Akbar ${ }^{2}$, Dysca \\ Ryesnanda Ayunita ${ }^{2}$, Farahiya Nabila ${ }^{2}$, Galuh Supriyadi', Inne Budi Kusuma Wardhani ${ }^{2}$ \\ ${ }^{1}$ Bagian Ilmu Kesehatan Masyarakat Fakultas Kedokteran Universitas Muhammadiyah Malang \\ ${ }^{2}$ Mahasiswa Fakultas Kedokteran Fakultas Kedokteran Universitas Muhammadiyah Malang
}

Email : gitasekarprihanti@gmail.com

\begin{abstract}
ABSTRAK
Angka Kematian Ibu(AKI) merupakansalah satu indikator yang peka dalam menggambarkan kesejahteraan masyarakat di suatu negara (Kementerian Kesehatan RI, 2016). AKI dinilai mulai dari masa kehamilan, persalinan, dan nifas (Fitrayani dkk, 2015; Parenden RD dkk, 2016).Ibu hamil yang sudah mengalami tanda-tanda persalinan diberikan kebebasan untuk meminta pertolongan persalinan ke tenaga kesehatan yang menyediakan pelayanan persalinan, namun ibu hamil yang tinggal di daerah urban lebih memilih persalinan di fasilitas kesehatan yang modern yang lebih baik seperti di rumah sakit. (Baba K et al, 2016). Hal inipun tentunya disebabkan oleh beberapa faktor yang mempengaruhi (Envuladu EA et al, 2013; Juley, 2014). Puskesmas XKota Y memiliki lima kelurahan yang meliputi, Bangsal, Betet, Blabak, Banaran, dan Pesantren. Sedangkan dari kelima kelurahan cakupan persalinan yang sangat rendah dari tahun ke tahun dimiliki oleh kelurahan Bangsal (Data Primer, 2016).Tujuan dari penelitian ini untuk mengetahui faktor-faktor yang berhubungan dengan pemilihan tempat persalinan di kelurahan Bangsal wilayah kerja Puskesmas Pesantren periode Januari-Juli 2016.Penelitian ini merupakan penelitian observasional analitik dengan pendekatan cross sectional. Populasi penelitian ini adalah semua ibu yang sudah melahirkan dalam kurun waktu Januari sampai dengan Juli 2016 yang bertempat tinggal di kelurahan Bangsal yang terletak di wilayah kerja Puskesmas XKota Y.Teknik pengambilan sampel dalam penelitian ini dilakukan dengan metode total sampling sebanyak 67 orang. Analisis ini menggunakan uji univariat, uji bivariat, multivariat serta uji regresi logistik. Dari uji multivariat didapatkan hubungan yang signifikan antara tingkat pendidikan ( $\mathrm{p}$ value $=0,000)$, pekerjaan $(\mathrm{p}$ value $=0,002)$, ekonomi ( $\mathrm{p}$ value $=0,000)$, dan umur $(\mathrm{p}$ value $=0,011)$ terhadap pemilihan tempat bersalin.Dari hasil uji multivariat, variabel yang paling berpengaruh terhadap pemilihan tempat bersalin adalah tingkat umur $\operatorname{Ibu}(\mathrm{OR}=0,027$ dan $\mathrm{p}$ value $=0,003)$. Besarnya kekuatan hubungan dari tingkat umur Ibu terhadap pemilihan tempat bersalin pada penelitian ini dapat dilihat melalui besarnya $R$ square sebanyak $84,2 \%$ sedangkan sisanya sebanyak 15,8\% dapat dijelaskan oleh berbagai faktor lain. Sehingga terdapat pengaruh dan hubungan antara tingkat umur ibu terhadap pemilihan tempat bersalin di rumah sakit.
\end{abstract}

Kata Kunci : pendidikan, pekerjaan, ekonomi, umur, pemilihan tempat bersalin, rumah sakit 


\section{ABSTRACT}

Maternal Mortality Rate (MMR) is one of the indicator that is sensitive in describing the nation's welfare of people (Kementerian Kesehatan RI, 2016). MMR assessed starting from pregnancy, childbirth, and postpartum (Fitrayani dkk, 2015; Parenden RD dkk, 2016).Pregnant women who are already experiencing signs of labor are given the freedom to request delivery assistance to health workers who provide labor services, but mostly pregnant women who live in urban areas are prefer to labor in modern health facilities such asin hospitals(Baba $\mathrm{K}$ et al, 2016). This also would be caused by several factors that affect to it (Envuladu EA et al, 2013; Juley, 2014). Puskesmas XKota Y has five areassuch as Bangsal,Betet, Blabak, Banaran, and Pesantren. Whereas from that areas, the low figure of maternity coverage from year to year, is owned by Bangsal's area (Primary Data, 2016). The purpose of this study was to determine the relationship between factors of affecting against selection maternity's place on hospital by pregnant women inBangsal's area PuskesmasXKota Yon period January until July 2016. This study using observational analytic with cross sectional approach. The population of this study was all the mothers who have given birth in the period January until July 2016 who reside in Bangsal's area. The sampling technique on this study conducted by the method of total sampling as many as 67 respondents. This study using analysisunivariate test, bivariate test, and multivariate logistic regression analysis test. From multivariate analysis have been found a significant relationship between the level of education $(p$ value $=0.000)$, occupation $(p$ value $=0.002)$, the economy $(p$ value $=0.000)$, and age $(\mathrm{p}$ value $=0.011)$ against on the selection of place of birth. From the results of multivariate analysis test, the variable that have most influencing is the level of age (with $\mathrm{OR}=0.027$ and $\mathrm{p}$ value $=0.003$ ). The magnitude of the relationship between the level of age against on the selection of maternity's place in this study can be seen by the amount of $\mathrm{R}$ square as much as $84.2 \%$ while the remaining $15.8 \%$ can be explained by other factors. So it can be concluded that there is influence and relationship between maternal ageagainst on the selection of maternity's place inhospital.

Keywords : education, employment, economic, age, selection birth place, hospitals

\section{PENDAHULUAN}

Penilaian terhadap status kesehatan dan kinerja dalam upaya kesehatan ibu dari tahun ke tahun penting untuk dilakukan pemantauan (Envuladu EA et al, 2013). Hal ini untuk menurunkan AKI (Angka Kematian Ibu) yang dinilai mulai dari masa kehamilan, persalinan, dan nifas (Fitrayani dkk, 2015; Parenden RD dkk, 2016). Hal ini dikarenakan AKI merupakan salah satu target pembangunan dan salah satu indikator yang peka dalam menggambarkan kesejahteraan masyarakat di suatu negara (Kementerian Kesehatan RI, 2016).

Kehamilan, persalinan, dan paska persalinan merupakan masalah kompleks. Salah satunya persalinan yang memiliki masalah dalam psikososio budaya, pelayanan kesehatan, tingkat ekonomi, tingkat pendidikan sehingga memerlukan perhatian yang khusus (Dhabi ZK et al,2015; Parenden RD dke, 2016).Pemerintah bersama masyarakat bertanggung jawab untuk menjamin bahwa setiap ibu memiliki akses terhadap pelayananankesehatan ibu yangberkualitas, mulai saat hamil, pertolongan persalinan oleh tenaga kesehatan terlatih, dan perawatan pasca persalinan bagi ibu dan bayi, perawatan khusus dan rujukan jika terjadi komplikasi serta akses terhadap Keluarga Berencana (KB) Media Y, 2014).

Capaian indikator persalinan oleh nakes dalam 10 tahun terakhir menunjukkan kecenderungan peningkatan, yaitu dari 74,27\% pada tahun 2004 menjadi 90,88\% pada 2013. Angka ini sudah mencapai target MDG's pada tahun 2015 sebesar 90\%. Cakupan persalinan oleh tenaga kesehatan yang cukup tinggi pada tahun 2013 yaitu sebesar 90,88\%, namun belum tentu semua persalinan tersebut bertempat di fasilitas pelayanan kesehatan yang sama(Kemenkes RI, 2016; Media Y, 2014; Parenden RD dkk, 2016). Hal ini dipengaruhi oleh beberapa faktor, seperti halnya ibu hamil dengan gaya hidup tinggi, pendidikan tinggi, tingkat ekonomi yang mumpuni, dukungan suami, dan lingkungan akan sangat mempengaruhi tempat bersalin terutama di fasilitas kesehatan yang lebih tinggi tingkatannya seperti rumah sakit (Baba K et al, 2016).

Ibu hamil yang sudah mengalami tandatandapersalinan diberikankebebasan untuk meminta 
pertolongan persalinan ke tenaga kesehatan yang menyediakan pelayanan persalinan, yaitu pustu, polindes/poskesdes, puskesmas, rumah sakit bahkan beberapa orang seperti lebih memilih dukun beranak dalam membantu persalinannya (Kementerian Kesehatan RI, 2016). Namun ibu hamil yang tinggal di daerah urban lebih memilih persalinan di fasilitas kesehatan yang modern yang lebih baik seperti di rumah sakit. Hal inipun tentunya disebabkan oleh beberapa faktor yang mempengaruhi Baba $\mathrm{K}$ et al, 2016).

Menurut Amardeep $T$ et al (2008) mengutip pendapat Andersen dengan teorinya "Andersen's Behavioral model of Health Service Utilation" mengemukakan bahwa keputusan untuk mengggunakan pelayanan kesehatan itu ada tiga komponen, yaitu (1) komponen predisposisi yang terdiri dari jarak, usia, struktur sosial dan kepercayaan kesehatan, (2) komponen enabling (pendukung) yang terdiri dari sumber daya keluarga (penghasilan keluarga, kemampuan membeli jasa pelayanan dan keikutsertaan dalam asuransi kesehatan), dan sumber daya masyarakat (jumlah sarana pelayanan kesehatan, jumlah tenaga kesehatan, rasio penduduk dan tenaga kesehatan, lokasi sarana kesehatan), (3) komponen need merupakan komponen yang paling langsung berpengaruh terhadap pemilihan pelayanan kesehatan.

Berdasarkan analisis teori tersebut maka dapat disimpulkan determinan keputusan ibu hamil untuk melakukan pemilihan pertolongan persalinan yang dipengaruhi oleh faktor karakteristik individu, seperti umur, pendidikan, pendapatan keluarga, riwayat persalinan, dan paritas. Selain itu juga dipengaruhi oleh dukungan keluarga, dan keterjangkauan terhadap pelayanan kesehatan (Juley, 2014).

Puskesmas X Kota Y memiliki lima kelurahan yang meliputi, Bangsal, Betet, Blabak, Banaran, dan Pesantren. Sedangkan dari kelima kelurahan cakupan persalinan yang sangat rendah dari tahun ke tahun dimiliki oleh kelurahan Bangsal. Bulan Januari sampai dengan Juni 2016 ini cakupan persalinan di kelurahan Bangsal sangat jauh dari target cakupan persalinan meskipun jumlah ibu hamil di daerah ini memiliki prevalensi terbesar dibandingkan dengan kelurahan lain (Data Primer, 2016). Dan hal ini juga ditunjang oleh data Pemantauan Wilayah Setempat Puskesmas X tahun 2015 lalu terutama di Kelurahan Bangsal yang menunjukkan data angka cakupan target persalinan di nakes sebesar $86 \%$ namun realisasi hanya $75.8 \%$ dengan angka kesenjangan -10.2\%(Data Primer, 2016).

Tujuan dari penelitian ini adalah untuk mengetahui faktor-faktor yang berhubungan dengan pemilihan tempat persalinan di kelurahan Bangsal wilayah kerja Puskesmas $\mathrm{X}$ periode Januari-Juli 2016. Hal ini dikarenakan faktor penyebab dari masalah ini belum diketahui secara pasti oleh pihak Puskesmas, bidan wilayah setempat, kader kesehatan setempat, maupun kelurahan. Oleh karena itu kami ingin melakukan penelitian mengenai beberapa faktor yang mempengaruhi pemilihan tempat persalinan di Rumah Sakit pada ibu hamil di kelurahan Bangsal yang terletak di wilayah kerja Puskesmas XKota Y. Penelitian ini diharapkan dapat menemui faktor permasalahanyang mempengaruhi sehingga dapat diperbaiki di bulan September sampai dengan Desember 2016 mendatang.

\section{METODE}

Penelitian ini dilakukan pada tanggal 16 Agustus 2016 dengan menggunakan data primer yang diperoleh melalui wawancara kuesioner dari Ibu yang sudah melahirkan pada Periode Januari Juli 2016 di Kelurahan BangsalKota Y(salah satu wilayah kerja Puskesmas X). Langkah-langkah dalam uji analisis ini meliputi uji univariat (frekuensi atau deskriptif) kemudian melakukan uji bivariat (uji chi square, uji fisher) untuk menganalisis variabel karakteristik tingkat pendidikan, pekerjaan, ekonomi, jarak akses, dan umur Ibu saat hamil. Dan terakhir, penelitian ini menggunakan analisis multivariat dengan uji regresi logistik (Dablan MS, 2009; Dablan MS, 2012).

Lokasi penelitian ini adalah kelurahan Bangsal yang terletak di wilayah kerja Puskesmas XKota Y pada bulan Agustus tahun 2016. Populasi penelitian ini adalah semua ibu yang sudah melahirkan dalam kurun waktu Januari sampai dengan Juli 2016 yang bertempat tinggal di kelurahan Bangsal yang terletak di wilayah kerja Puskesmas XKota Y.Penelitian ini menggunakan sebanyak 67 orang (Data Primer, 2016).

Sampel penelitian ini adalah semua ibu yang sudah melahirkan dalam kurun waktu Januari sampai dengan Juli 2016 yang bertempat tinggal di kelurahan Bangsal yang terletak di wilayah kerja Puskesmas X Kota $\mathrm{Y}$ yang memenuhi kriteria inklusi.Teknik pengambilan sampel dalam penelitian 
ini dilakukan dengan metode total sampling (Dablan MS, 2009). Metode ini dilakukan dengan mengambil sampel secara home visite ke rumah ibu yang sudah melahirkan dalam kurun waktu Januari sampai dengan Juli 2016 yang memenuhi dengan kriteria: a. Kriteria Inklusi:

1. Semua ibu hamil yang memenuhi kriteria inklusi

2. Ibu hamil yang mau berpartisipasi dalam penelitian ini.

b. Kriteria Eksklusi:

1. Ibu hamil dengan riwayat sc kurang dari 2 tahun.

2. Ibu hamil dengan kehamilan beresiko tinggi, seperti ibu hamil dengan HIV/AIDS, DM tipe 2, hepatitis B, gemelli, riwayat sc kurang dari 2 tahun, ibuhamil dengan asma, TB, dan ibu hamil dengan penyakit jantung.

3. Ibu dengan usia $>40$ tahun

4. Ibu hamil yang tidak mau berpartisipasi dalam penelitian ini.

Variabel tergantung dari penelitian ini adalah pemilihan tempat bersalin di kelurahan Bangsal wilayah Puskesmas XKota Y yang dibagi rumah sakit dan non rumah sakit (Risanto S, 2009). Sedangkan variabel bebas dari penelitian ini adalah faktor-faktor (usia, pekerjaan, tingkat ekonomi, tingkat pendidikan, umur, jarak akses) (Mabdi SS et al. 2010; Rerey HV \& Susanto N, 2012) yang mempengaruhi pemilihan tempat bersalin warga kelurahan Bangsal. Instrumen penelitian terdiri dari kuesioner, pengumpulan data dan diperlukan alat tulis dan buku untuk mengumpulkan data yang ada, serta Laptop dengan software SPSS 22 for windows untuk mengolah data yang dikumpulkan.

\section{HASIL}

\section{A. Karakteristik Responden}

\section{(Analisis Univariat)}

Tabel1. Distribusi FrekuensiKarakteristik Tingkat Pendidikan Ibu

\begin{tabular}{lll}
\hline Tingkat & N & \% \\
Pendidikan & & 22,4 \\
\hline Primer & 15 & 77,6 \\
Sekunder & 52 & 100,0 \\
Total & 67 & \\
\hline
\end{tabular}

(Data Primer, 2016)
Tabel 2. Distribusi FrekuensiKarakteristik Pekerjaan Ibu

\begin{tabular}{lll}
\hline Pekerjaan Ibu & N & \% \\
\hline Tidak Bekerja & 45 & 67,2 \\
Bekerja & 22 & 32,8 \\
Total & 67 & 100,0 \\
\hline
\end{tabular}

(Data Primer, 2016)

Tabel3. Distribusi Frekuensi Karakteristik Ekonomi Keluarga

\begin{tabular}{lll}
\hline $\begin{array}{l}\text { Ekonomi } \\
\text { Keluarga }\end{array}$ & $\mathbf{N}$ & $\mathbf{\%}$ \\
\hline < UMK & 29 & 43,3 \\
$>$ UMK & 38 & 56,7 \\
Total & 67 & 100,0 \\
\hline
\end{tabular}

(Data Primer, 2016)

Tabel 4. Distribusi Frekuensi Karakteristik Jarak Akses

\begin{tabular}{lll}
\hline Jarak & $\mathbf{N}$ & $\mathbf{\%}$ \\
\hline$<\mathbf{5 0 0} \mathbf{~ m}$ & 8 & 11,9 \\
$>\mathbf{5 0 0} \mathbf{~ m}$ & 59 & 88,1 \\
Total & 67 & 100,0 \\
\hline
\end{tabular}

(Data Primer, 2016)

Berdasarkan tabel1 dari 67 responden didapatkan bahwa sebagian besar responden memiliki tingkat pendidikan sekunder sebanyak 52orang $(77,6 \%)$ dan tingkat pendidikan primer sebanyak 15 orang $(22,4 \%)$. Berdasarkan tabel 2 dari 67 responden didapatkan bahwa sebagian besar responden sebanyak 45 orang $(67,2 \%)$ tidak bekerja dan responden yang bekerja sebanyak 22 orang $(32,8 \%)$.

Berdasarkan tabel 3 dari 67 responden didapatkan bahwa sebagian besar ekonomi keluarga responden di wilayah kelurahan Bangsal lebih dari UMK (Upah Minimum Kabupaten/ Kota) Kota Y sebanyak 38 orang $(56,7 \%)$, sedangkan ekonomi keluarga responden yang kurang dari UMK sebanyak 29 orang $(43,3 \%)$. 
Tabel5. Distribusi Frekuensi Karakteristik Umur Ibu saat Hamil

\begin{tabular}{lll}
\hline Umur & $\mathbf{N}$ & $\mathbf{\%}$ \\
\hline $\mathbf{2 0}$ th & 15 & 22,4 \\
$\mathbf{2 0 - 4 0}$ th & 52 & 77,6 \\
Total & 67 & 100,0 \\
\hline
\end{tabular}

(Data Primer, 2016)

Tabel 6. Distribusi Frekuensi Karakteristik Pemilihan Tempat Bersalin

\begin{tabular}{lll}
\hline Umur & N & \% \\
\hline Non Rumah Sakit & 39 & 58,2 \\
Rumah Sakit & 28 & 41,8 \\
Total & 67 & 100,0 \\
\hline
\end{tabular}

(Data Primer, 2016)

Berdasarkan tabel 4 dari 67 responden didapatkan bahwa sebagian besar responden memiliki jarak akses (terutama ke fasilitas kesehatan) lebih dari $500 \mathrm{~m}$ sebanyak 59 orang $(88,1 \%)$, sedangkan responden yang memiliki jarak akses kurang dari $500 \mathrm{~m}$ sebanyak 8 orang (11,9\%). Berdasarkan tabel 5 dari 67 responden didapatkan bahwa sebagian besar karakteristik umur responden saat hamil pada Kelurahan Bangsal pada umur 2040 tahun sebanyak 52 orang $(77,6 \%)$, sedangkan responden yang memiliki umur $<20$ th tahun sebanyak 15 orang $(22,4 \%)$.

Berdasarkan tabel 6 dari 67 responden didapatkan bahwa sebagian besar karakteristik pemilihan tempat bersalinpada rumah sakit sebanyak 28 orang $(58,2 \%)$, sedangkan karakteristik pemilihan tempat bersalinpada non rumah sakit sebanyak 39 orang $(41,8 \%)$.

\section{B. Analisis Bivariat}

Berdasarkan analisis data bivariat terhadap pemilihan tempat bersalin, menunjukkan bahwa responden yang memiliki tingkat pendidikan sekunder sebanyak 52 orang $(77,6 \%)$ telah menempati urutan terbesar pada karakteristik tingkat pendidikan terakhir Ibu yang sudah melahirkan pada Periode Januari - Juli 2016 di Kelurahan Bangsal Kota Kota Y. Pada tingkat pendidikan sekunder ini sebanyak 24 orang $(30,3 \%)$ memilih Non Rumah Sakit (Bidan/ Puskesmas) sedangkan sebanyak 28 orang $(21,7 \%)$ memilih Rumah Sakit.
Pada tingkat pendidikan primersebanyak 15 orang $(8,7 \%)$ memilih Non Rumah Sakit (Bidan/ Puskesmas) dan tidak ada yang memilih Rumah Sakit.

Analisis bivariat ini menggunakan tabel $2 \mathrm{x}$ 2 dengan expected count kurang dari 5 , sehingga pada uji analisis chi square didapatkan hasil $p$-value sebesar 0,000 yang artinya terdapat hubungan antara karakteristik tingkat pendidikan Ibu terhadap pemilihan tempat bersalin pada penelitian ini. Korelasi yang digunakan adalah $\mathrm{RO}$ yaitu sebesar 2,16 dengan IK 95\% 1,615-2,906. Artinya pengaruh karakteristik tingkat pendidikan Ibu terhadap pemilihan tempat bersalin memiliki probabilitas sebesar 68,35\%.

Berdasarkan analisis data bivariat terhadap pemilihan tempat bersalin, menunjukkan bahwa responden Ibu yang tidak bekerja sebanyak 45 orang $(67,2 \%)$ menempati urutan terbesar pada karakteristik pekerjaan Ibu yang sudah melahirkan pada Periode Januari - Juli 2016 di Kelurahan Bangsal Kota Kota Y. Pada karakteristik responden yang tidak bekerja, didapatkan 32 orang $(26,2 \%)$ memilih Non Rumah Sakit (Bidan/ Puskesmas) sedangkan sebanyak 13 orang $(18,8 \%)$ memilih Rumah Sakit. Pada karakteristik responden yang memiliki pekerjaan sebanyak 22 orang $(32,8 \%)$ didapatkan hasil sebanyak 7 orang $(12,8 \%)$ memilih Non Rumah Sakit (Bidan/ Puskesmas) sedangkan sebanyak 15 orang $(9,2 \%)$ memilih Rumah Sakit.

Analisis bivariat ini menggunakan tabel $2 \mathrm{x}$ 2 dengan expected count kurang dari 5, sehingga pada uji analisis chi square didapatkan hasil $p$-value sebesar 0,002 yang artinya terdapat hubungan antara karakteristik pekerjaan Ibu terhadap pemilihan tempat bersalin pada penelitian ini.Korelasi yang digunakan adalah RO yaitu sebesar 5,27 dengan IK 95\% 1,748-15,921. Artinya pengaruh karakteristik pekerjaan Ibu terhadap pemilihan tempat bersalin memiliki probabilitas sebesar $84,05 \%$.

Berdasarkan analisis data bivariat terhadap pemilihan tempat bersalin, menunjukkan bahwa sebagian besar responden Ibu yang sudah melahirkan pada Periode Januari - Juli 2016 di Kelurahan BangsalKota Ymemiliki tingkat ekonomi > UMK (Upah Minimum Kabupaten/ Kota) Kota Ysebanyak 38 orang $(56,7 \%)$. Pada tingkat ekonomi > UMK didapatkan sebanyak 10 orang $(22,1 \%)$ memilih Non Rumah Sakit (Bidan/ Puskesmas) sedangkan sebanyak 28 orang $(15,9 \%)$ memilih 
Rumah Sakit. Sedangkan pada tingkat ekonomi < UMK didapatkan sebanyak 29 orang (16,9\%) memilih Non Rumah Sakit (Bidan/ Puskesmas) dan tidak ada yang memilih Rumah Sakit.

Analisis bivariat ini menggunakan tabel $2 \mathrm{x}$ 2 dengan expected count kurang dari 5, sehingga pada uji analisis chi square didapatkan hasil p-value sebesar 0,000 yang artinya terdapat hubungan antara karakteristik tingkat ekonomi terhadap pemilihan tempat bersalin pada penelitian ini.Korelasi yang digunakan adalah RO yaitu sebesar 3,80 dengan IK 95\% 2,232-6,469. Artinya pengaruh karakteristik tingkat ekonomi terhadap pemilihan tempat bersalin memiliki probabilitas sebesar 79,16\%.

Berdasarkan analisis data bivariat terhadap pemilihan tempat bersalin, menunjukkan bahwa sebagian besar responden Ibu yang sudah melahirkan pada Periode Januari - Juli 2016 di Kelurahan BangsalKota Ymemiliki jarak akses > $500 \mathrm{~m}$ ke Puskesmas sebanyak 59 orang (88,1\%). Pada jarak akses $>500 \mathrm{~m}$ didapatkan sebanyak 37 orang (34,3\%) memilih Non Rumah Sakit (Bidan/ Puskesmas) sedangkan sebanyak 22 orang (24,7\%) memilih Rumah Sakit. Pada jarak akses $<500 \mathrm{~m}$ didapatkan sebanyak 2 orang (4,7\%) memilih Non Rumah Sakit (Bidan/ Puskesmas) dan sebanyak 6 orang (3,3\%) memilih Rumah Sakit. Analisis bivariat ini menggunakan tabel 2 × 2 dengan expected count kurang dari 5 dan lebih dari 20\% (50\%). Sehingga pada penelitian ini tidak dapat menggunakan uji analisis chi square dan harus menggunakan uji analisis Fisher's Exact Test. Pada uji analisis Fisher's Exact
Test didapatkan nilai Significancy adalah0,060 untuk 2-sided (two tail) dan 0,050 untuk 1-sided (one tail). Karena nilai p-value $>0,05$ maka kesimpulannya tidak terdapat hubungan antara jarak akses terhadap pemilihan tempat bersalin pada penelitian ini.Korelasi yang digunakan adalah RO yaitu sebesar 0,19 dengan IK 95\% 0,037-1,069. Artinya pengaruh jarak akses terhadap pemilihan tempat bersalin memiliki probabilitas sebesar 15,96\%.

Berdasarkan analisis data bivariat terhadap pemilihan tempat bersalin, menunjukkan bahwa sebagian besar responden yang memiliki umur dalam rentang 20-40 tahun sebanyak 52 orang (77,6\%). Pada tingkat umur dalam rentang 20-40 tahun didapatkan sebanyak 26 orang (30,3\%) memilih Non Rumah Sakit (Bidan/ Puskesmas) sedangkan sebanyak 26 orang $(21,7 \%)$ memilih Rumah Sakit. Sedangkan pada tingkat umur rentang $<20$ tahun sebanyak 15 orang $(22,4 \%)$, didapatkan sebanyak 13 orang (8,7\%) memilih Non Rumah Sakit (Bidan/ Puskesmas) sedangkan sebanyak 2 orang (6,3\%) memilih Rumah Sakit. Analisis bivariat ini menggunakan tabel $2 \times 2$ dengan expected count kurang dari 5, sehingga pada uji analisis chi square didapatkan hasil p-value sebesar 0,011 yang artinya terdapat hubungan antara karakteristik umur Ibu terhadap pemilihan tempat bersalin pada penelitian ini.Korelasi yang digunakan adalah RO yaitu sebesar 6,50 dengan IK 95\% 1,332-31,710. Artinya pengaruh karakteristik umur Ibu terhadap pemilihan tempat bersalin memiliki probabilitas sebesar $86,66 \%$.

Tabel 7. Resume Analisis Bivariat: Variabel Bebas dengan Variabel Terikat

\begin{tabular}{cccccccccc}
\hline & & \multicolumn{3}{c}{ NON RS } & \multicolumn{2}{c}{ RS } & & \multicolumn{2}{c}{ IK 95\% } \\
\cline { 3 - 9 } Pendidika & Primer & 15 & 8,7 & 0 & 6,3 & 0,000 & 2,16 & 1,615 & 2,906 \\
n & Sekunder & 24 & 30,3 & 28 & 21,7 & Chi Square & & & \\
Pekerjaan & Tidak bekerja & 32 & 26,2 & 13 & 18,8 & 0,002 & 5,27 & 1,748 & 15,921 \\
& Bekerja & 7 & 12,8 & 15 & 9,2 & Chi Square & & & \\
Ekonomi & $<$ UMK & 29 & 16,9 & 0 & 12,1 & 0,000 & 3,80 & 2,232 & 6,469 \\
& $>$ UMK & 10 & 22,1 & 28 & 15,9 & Chi Square & & & \\
Jarak & $<500 \mathrm{~m}$ & 2 & 4,7 & 6 & 3,3 & 0,60 & 0,19 & 0,037 & 1,069 \\
& $>500 \mathrm{~m}$ & 37 & 34,3 & 22 & 24,7 & Fisher & & & \\
Umur & $<20$ th & 13 & 8,7 & 2 & 6,3 & 0,011 & 6,50 & 1,332 & 31,710 \\
& $20-40 \mathrm{th}$ & 26 & 30,3 & 26 & 21,7 & Chi Square & & & \\
\hline
\end{tabular}

(Data Primer, 2016) 
Tabel 8. Equasi Variabel Uji Regresi Logistik

\begin{tabular}{cccccccc}
\hline & & B & Wald & Sig. & OR & \multicolumn{2}{c}{ 95\% C.I.for EXP(B) } \\
\cline { 3 - 7 } & & & & & & Lower & Upper \\
\hline \multirow{2}{*}{\begin{tabular}{c} 
Step \\
\cline { 2 - 7 }
\end{tabular}} & pend(1) & $-19,564$ &, 000 &, 998 &, 000 &, 000 &. \\
\cline { 2 - 7 } & pek(1) & $-1,914$ & 2,363 &, 124 &, 148 &, 013 & 1,693 \\
\cline { 2 - 7 } & umur(1) & $-3,595$ & 8,756 &, 003 &, 027 &, 003 &, 297 \\
\cline { 2 - 7 } & ekonomi(1) & $-22,227$ &, 000 &, 997 &, 000 &, 000 &. \\
\hline
\end{tabular}

(Data Primer, 2016)

\section{A. Analisis Multivariat}

Analisis multivariat pada penelitian ini membahas tentang hubungan antara banyak variabel bebas dengan variabel terikat (Dahlan MS, 2012). Hal ini sangat perlu sekali mengingat meskipun dari pemodelan regresi logistik univariat telah diketahui bahwa variabel bebas berupa karakteristik tingkat pendidikan, pekerjaan, ekonomi dan umur Ibu berpengaruh secara signifikan terhadap variabel terikat, namun belum diketahui bagaimana hubungan antar variabel tersebut. Karena jika ternyata hubungannya sangat erat, maka dimungkinkan salah satu dari variabel tersebut akan menjadi tidak signifikan lagi pengaruhnya terhadap variabel terikat. Oleh karena itu, perlu dilakukan suatu pemodelan regresi dengan memasukkan semua variabel tersebut secara bersama-sama untuk memeriksa ada atau tidaknya hubungan antar variabel tersebut (Dahlan MS, 2009; Dahlan MS, 2012).

Terdapat dua analisis multivariat yang sering digunakan dalam penelitian kedokteran dan kesehatan, yaitu analisis regresi logistik dan analisis regresi linier. Pemilihan kedua analisis tersebut ditentukan oleh skala pengukuran variabel terikatnya. Karena variabel terikat pada penelitian kami berupa variabel kategorik, maka regresi yang digunakan adalah analisis regresi logistik. Data variabel yang dimasukkan dalam analisis multivariat adalah variabel yang pada analisis bivariat mempunyai nilai $\mathrm{p}$-value $<0,25$. Berikut ini adalah data dari uji regresi logistik seperti pada tabel 8 di atas. Dari tabel di atas didapatkan variabel yang paling berpengaruh terhadap pemilihan tempat bersalin adalah tingkat umur Ibu. Kekuatan hubungan dapat dilihat dari nilai OR dan p (Sig) 0,003. Kekuatan hubungan variabel yang paling berpengaruh terhadap pemilihan tempat bersalin yaitu tingkat umur Ibu sebesar 0,027. Berdasarkan hasil penghitungan dan persamaan regresi logistik di atas maka menunjukkan bahwa variabel umur Ibu berpengaruh negatif, hal tersebut berarti ibu dengan umur $<20$ tahun dapat mempengaruhi pemilihan tempat bersalin yang tidak tepat. Besarnya kekuatan hubungan dari variabel bebas (umur ibu) yang berpengaruh terhadap variabel terikat pada penelitian ini dapat dilihat melalui besarnya $\mathrm{R}$ square sebanyak $84,2 \%$ sedangkan sisanya sebanyak 15,8\% dapat dijelaskan oleh berbagai faktor lain.

Tabel 9. R Square

\begin{tabular}{|c|c|c|c|}
\hline \multicolumn{4}{|c|}{ Model Summary } \\
\hline Step & $\begin{array}{c}-2 \log \\
\text { likelihood }\end{array}$ & $\begin{array}{l}\text { Cox \& } \\
\text { Snell R } \\
\text { Square }\end{array}$ & $\begin{array}{c}\text { Nagelkerke } \\
\text { R Square }\end{array}$ \\
\hline 1 & $25,283^{a}$ & 625 & ,842 \\
\hline
\end{tabular}

(Data Primer, 2016)

\section{PEMBAHASAN}

Berdasarkan data kami yang tercantum dalam tabel 7 yang dihasilkan dari penelitian kami di kelurahan Bangsal pada bulan Agustus 2016 dapat disimpulkan bahwa hasil p-value pada tabel tingkat pendidikan sebesar 0,000 yang artinya terdapat hubungan antara karakteristik tingkat pendidikan terhadap pemilihan tempat bersalin pada penelitian ini. Hal ini sesuai dengan penelitian yang dilakukan oleh Envuladu EA et al(2013) yang mengatakan bahwa pendidikan formal sangat penting bagi seorang ibu karena dengan pendidikan yang baik maka ibu mempunyai wawasan berpikir yang luas dan baik tentang pemanfaatan pelayanan kesehatan. Tingkat pendidikan dan sumber informasi yang diterima mempengaruhi pengetahuan, dalam hal ini pengetahuan mengenai kehamilan dan persalinan sehingga pengetahuan yang didapat 
tentang kehamilan, persalinan, pemilihan penolong persalinan, dan pemilihan tempat persalinan lebih baik (Parenden RD dkk, 2016).

Hal ini juga didukung oleh studi yang menyatakan bahwa adanya pengetahuan dan edukasi memiliki pengaruh sangat penting karena wanita yang memiliki pengetahuan tinggi akan cenderung memilih tempat bersalin yang lebih bagus daripada wanita dengan pendidikan yang rendah (Mezmur Het al,2013). Selain itu teori lain yang mendukung tingkat pendidikan dapat mempengaruhi pemilihan tempat persalinan adalah teori yang menyatakan bahwa semakin tinggi tingkat pendidikan yang dimiliki oleh orangtua terutama ibu hamil maka akan sangat mempengaruhi kepemilihan tempat bersalin yang lebih lengkap dan lebih baik(Astuti AP dkk, 2014).Hal ini diakibatkan oleh aktifnya ibu yang hendak melahirkan dalam mencari informasi mengenai kekurangan dan kelebihan suatu tempat persalinan. Sedangkan ibu hamil yang memiliki tingkat pendidikan yang rendah lebih memilih tempat persalinan di tenaga kesehatan dengan tipe non rumah sakit (Mezmur Het al,2013).

Berdasarkan pengujian analisis regresi logistiknya sesuai tabel 8 menunjukkan data bahwa pendidikan sang ibu tidak terlalu signifikan mempengaruhi pemilihan tempat persalinan.Hasil analisis regresi logistik ini menghasilkan OR 0,000dengan p sebesar 0,998. Hal ini dapat dipengaruhi oleh beberapa faktor yang mempengaruhi seperti jauhnya jarak tempat tinggal ke rumah sakit dan lebih dekat dengan fasilitas kesehatan non rumah sakit. Selain itu keinginan keluarga untuk menjenguk di tempat bersalin yang terdekat seusai proses persalinan berlangsung juga masih tinggi (Yegezu RT et al, 2014; Baba K et al, 2016).

Berdasarkan data kami yang tercantum dalam tabel 7 yang dihasilkan dari penelitian kami di kelurahan Bangsal pada bulan Agustus 2016 dapat disimpulkan bahwa hasil p-value pada karakteristik pekerjaan sebesar 0,002 yang artinya terdapat hubungan antara karakteristik pekerjaan terhadap pemilihan tempat bersalin pada penelitian ini. Hal ini didukung oleh penelitian yang dilakukan olehRerey HV \& Susanto N (2012) yang menyatakan bahwa dengan bekerja ibu akan selalu mendapatkan informasi dan saling bertukar pikiran dengan teman di kantornya, tentang ANC, pemilihan penolong persalinan, pemilihan tempat persalinan. Sehingga pekerjaan juga akan mempengaruhi ibu dalam memilih tempat bersalin (Rerey HV \& Susanto N, 2012). Menurut Eastern Mediterance Health Journal mnyatakan bahwa pekerjaan akan sangat berpengaruh bahwa dengan bekerja ibu akan selalu mendapatkan informasi dan saling bertukar pikiran dengan teman baru, tempat baru sehingga akan mempengaruhi seorang ibu yang hamil untuk memilih dan menentukan tempat bersalin (Mahdi SS et al. 2010).

Berdasarkan pengujian analisis regresi logistiknya sesuai tabel 8menunjukkan data bahwa tingkat pekerjaan sang ibu tidak signifikan mempengaruhi pemilihan tempat persalinan.Hasil analisis regresi logistik ini menghasilkan p sebesar 0,148 . Hal ini dikarenakan faktor pekerjaan dipengaruh oleh banyak faktor lain dalam analisis regresi logistiknya sehingga hasil tidak signifikan. Hal ini bisa sesuai dengan penelitian yang dilakukan oleh Yegezu RT et al (2014) yang menyatakan bahwa tingkat pekerjaan responden dalam penelitiannya tidak mempengaruhi tempat pemilihan bersalin di daerah penelitian ini dilakukan. Hal ini banyak dipengaruhi oleh beberapa faktor yang mempengaruhi seperti jauhnya jarak tempat tinggal ke rumah sakit dan lebih dekat dengan fasilitas kesehatan non rumah sakit.

Berdasarkan data kami yang tercantum dalam tabel 7 yang dihasilkan dari penelitian kami di kelurahan Bangsal pada bulan Agustus 2016 dapat disimpulkan bahwa hasil p-value sebesar 0,011 yang artinya terdapat hubungan antara karakteristik umur Ibu terhadap pemilihan tempat bersalin pada penelitian ini. Hal ini diperkuat oleh penelitian yang dilakukan Rerey HV \& Susanto N (2012) yang menunjukkan adanya hubungan antara umur dengan pemilihan pelayanan kesehatan dalam persalinannya. Semakin dewasa umur seseorang maka akan semakin mengerti akan pilihannya dalam menentukan tempat persalinan. Sedangkan menurut studi kasus di India menyatakan bahwa perempuan yang dewasa akan memiliki pemikiran yang lebih matang daripada perempuan yang lebih muda dalam hal menentukan tempat bersalin. Hal ini bisa dikarenakan karena wanita lebih muda lebih mudah terpengaruh oleh opini dari tetangga,mertua, dan lingkungan sekitarnya (Kaul S et al, 2012).

Berdasarkan tabel 8 menunjukkan data bahwa tingkat usia signifikan mempengaruhi 
pemilihan tempat persalinan sesuai hasil analisis regresi logistic dengan $\mathrm{p}$ 0,027. Hal ini didukung oleh penelitian di Kenya bahwa persalinan yang dialami oleh ibu hamil dengan umur kurang dari 20 tahun lebih dipengaruhi oleh keputusan orang tua dari ibu hamil tersebut daripada keputusan yang diambil atas kesadaran diri sendiri dari ibu hamil tersebut (Kaul S et al, 2012; Juley, 2014).

Berdasarkan data kami yang tercantum dalam tabel 7 yang dihasilkan dari penelitian kami di kelurahan Bangsal pada bulan Agustus 2016 dapat disimpulkan bahwa hasil p-value sebesar 0,000 yang artinya terdapat hubungan antara karakteristik tingkat ekonomi terhadap pemilihan tempat bersalin pada penelitian ini. Data ini ditunjang oleh penelitian yang dilakukan Rerey HV \& Susanto N (2012) bahwa tingkat ekonomi sangat mempengaruhi pemilihan tempat persalinan yang dikarenakan oleh kemampuan biaya masing-masing individu dalam pembiayaan. Hal ini juga didukung oleh pernyataan Okan CA et al(2015) yang menyatakan bahwa semakin tinggi tingkat ekonomi seseorang dalam menentukan tempat persalinan maka semakin tinggi pula fasilitas kesehatan yang diinginkan. Hal ini berhubungan dengan rasa kenyamanan yang diinginkan, kelengkapan fasilitas, dan biaya yang dapat dijangkau oleh keuangan tiap orang ibu hamil dan pasangan dalam menentukan tempat persalinan nanti (Okan CA et al,2015; Dhahi ZK et al,2015).

Berdasarkan tabel 8 menunjukkan data bahwa tingkat ekonomi tidak terlalu signifikan mempengaruhi pemilihan tempat persalinan sesuai hasil analisis regresi logistik dengan OR 0,000 dan p 0,997. Hal ini banyak dipengaruhi oleh beberapa faktor yang mempengaruhi seperti jauhnya jarak tempat tinggal ke rumah sakit dan lebih dekat dengan fasilitas kesehatan non rumah sakit(Yegezu RT et al, 2014).

Berdasarkan data kami yang tercantum dalam tabel 7 yang dihasilkan dari penelitian kami di kelurahan Bangsal pada bulan Agustus 2016 dapat disimpulkan bahwa hasil p-value $>0,05$ maka kesimpulannya tidak terdapat hubungan antara jarak akses terhadap pemilihan tempat bersalin pada penelitian ini. Hasil ini sesuai dengan penelitian Rusnawati (2012) yang menyatakan bahwa tidak terdapat hubungan yang bermakna antara jarak dengan pemilihan tempat bersalin karena dapat dipengaruhi oleh beberapa faktor lainnya. Seperti yang dipaparkan dalam penelitian di Ethiopia menyatakan bahwa seorang ibu dengan pendidikan yang baik lebih memilih melahirkan di pelayanan kesehatan yang menurutnya lebih baik meskipun jarak yang harus ditempuh lebih jauh (Mezmur Het al,2013).

\section{KESIMPULAN}

Berdasarkan hasil penelitian dan pembahasan dapat disimpulkan bahwa:

a. Terdapat hubungan antara tingkat pendidikan terakhir ibu dengan pemilihan tempat bersalin pada penelitian ini dengan analisis bivariat $(p$ value $=0,000$ atau $<0.05$ )

b. Tidak terdapat hubungan antara tingkat pendidikan terakhir ibu dengan pemilihan tempat bersalin pada penelitian ini analisis multivariat (nilai OR 0,000 dan $\mathrm{p}$ value $=$ $0,998$ atau $<0.05)$.

c. Terdapat hubungan antara karakteristik pekerjaan ibu dengan pemilihan tempat bersalin pada penelitian ini analisis bivariat (nilai $\mathrm{p}$ value $=0,002$ atau $<0.05)$.

d. Tidak terdapat hubungan antara karakteristik pekerjaan ibu dengan pemilihan tempat bersalin pada penelitian ini analisis multivariat (nilai $\mathrm{p}$ value $=0,124$ atau $<0.05)$.

e. Terdapat hubungan antara karakteristik umur ibu dengan pemilihan tempat bersalin pada penelitian ini analisis bivariat ( nilai $\mathrm{p}$ value $=$ $0,011$ atau $<0.05)$.

f. Terdapat hubungan antara karakteristik umur ibu dengan pemilihan tempat bersalin pada penelitian ini analisis multivariat ( $\mathrm{p}$ value $=$ 0,003 atau $<0.05$ ).

g. Terdapat hubungan antara karakteristik tingkat ekonomi rumah tangga ibu dengan pemilihan tempat bersalin pada penelitian ini analisis bivariat (nilai $\mathrm{p}$ value $=0,000$ atau $<0.05$ ).

h. Tidak terdapat hubungan antara karakteristik tingkat ekonomi rumah tangga ibu dengan pemilihan tempat bersalin pada penelitian ini analisis multivariat $($ nilaiOR $=0,000$, dan $\mathrm{p}$ value 0,997 atau $<0.05)$.

i. Tidak terdapat hubungan yang signifikan antara jarak akses ke faslitas kesehatandengan pemilihan tempat bersalin pada penelitian ini (dengan 
nilai OR 0,000 dan $\mathrm{p}$ value $=0,997$ atau $<$ $0.05)$.

\section{SARAN}

Hasil penelitian ini diharapkan dapat digunakan sebagai sumber informasi bagi institusi kesehatan agar dapat lebih meningkatkan pelayanannya pada masing-masing bagian institusinya, secara berkala melakukan refreshing kader guna meningkatkan pengetahuan kader dan memberikan reward pada kader yang aktif sehingga bisa menjadi motivasi kader untuk lebih aktif, melakukan penyuluhan dengan menyediakan petugas pelayanan khusus dan bekerjasama dengan organisasi kemasyarakatan seperti PKK.

Perlu dilakukan penelitian lebih lanjut menggunakan variabel yang belum dilakukan dalam penelitian ini seperti kehadiran tenaga kesehatan, serta penelitian kualitatif tentang kendala-kendala atau masalah yang mempengaruhi sehingga bisa diperoleh informasi yang lebih mendalam tentang faktor-faktor yang berhubungan dengan pemilihan tempat bersalin.

\section{DAFTAR PUSTAKA}

Amardeep T et al,2008. Where To Deliver? Analysis Of Choice Of Delivery Location From A National Survey In India. BMC Public Health 2008, 8:29, pp. 1-8.

Astuti AP dkk, 2014. Analisis Alasan Pemilihan Penolong Persalinan oleh Ibu Bersalin di Kabupaten Semarang. Manajemen Kesehatan Indonesia, Vol. 02 No. 3, hal: 253-60.

Baba $\mathrm{K}$ et al, 2016. A cross-sectional survey of poliecies guiding second stage labor in urban japanese hospitals, clinics, and midwivery births centers. BMC Pregnancy and Childbirth. Vol. 16, No. 37, pp: 1-13.

Dahlan MS, 2009. Statistik Untuk Kedokteran dan Kesehatan: Deskriptif, Bivariat, dan Multivariat, Dilengkapi Aplikasi dengan Menggunakan SPSS/ Muhamad Sopiyudin Dahlan. Salemba Medika. Jakarta. Hal: 12293

Dahlan MS, 2012. Analisis Multivariat Regresi Logistik disertai Praktik dengan Program SPSS dan Stata. PT Epidemiologi Indonesia. Jakarta. Hal: 21-61.
Data Primer, 2016.

Dhahi ZK et al, 2015. A Study on Pregnant Women's Satisfaction With Primary Health Care Services In Basra. International Journal of Reasearch In Humanities, Arts, and Literature. Vol 3, Issue 1, pp: 7-20.

Envuladu EA et al, 2013. Factors Determining The Choice Of A Place Of Delivery Among Pregnant Women In Russia Village Of Jos North, Nigeria: Achieving The MDGs 4 and 5. Department of Community Medicine, Jos University Teaching Hospital, Plateau state. Doctors on the Move-Africa International. International Journal of Medicine and Biomedical Research. Vol 2 Issue 1, pp: 23-7.

Fitrayani dkk, 2015. Penyebab Rendahnya Kelengkapan Kunjungan Antenatal Care Ibu Hamil Di Wilayah Kerja Puskesmas Pegambiran. Jurnal Kesehatan Masyarakat Andalas. Fakultas Kesehatan Masyarakat Universitas Andalas. Hal: 1-9.

Juley, 2014. Factors Influencing Delivery Practices among Pregnant Women in Kenya: A Case of Wareng' District in Uasin Gishu County, Kenya. International Journal of Innovation and Scientific Research ISSN 2351-8014 Vol. 10 No. 1 Oct. 2014, pp. 50-8

Kaul S et al, 2012. Delivery at Home versus Delivery at A Health Care Facility- A Case Study of Bihar India. Selected Paper Prepared For Presentation At Agricultural \& Apllied Economics Association's 2012 AAEA Annual Meeting at Seattle Washington, pp. 12-9.

Kementerian Kesehatan RI, 2016. Profil KesehatanIndonesia 2016. Kementerian Kesehatan Republik Indonesia.

Mahdi SS et al. 2010. A Study On Preference And Practices Of Women Regarding Place Of Delivery. Eastern Mediterranean Health Journal La Revue De Santé De La Méditerranée Orientale. Directorate of Health Services, Basra, Iraq. Department of Community Medicine, College of Medicine, University of Basra, Basra, Iraq. EMHJ Vol. 16, No. 8, pp. 6-20.

Media Y, 2014. Kualitas Pelayanan Kesehatan Ibu Hamil dan Bersalin di Daerah Terpencil 
(Studi Kasus di Nagari Batu Bajanjang, Kabupaten Solok, Provinsi Sumatera Barat). Badan Perencanaan Pembangunan Daerah Provinsi Sumatera Barat. Jurnal Bina Praja. Vol. 6, No. 1, hal: 43-52.

Mezmur Het al,2013. Factors Affecting Choice of Delivery Place among Women in Haramaya Woreda, Oromia Regional State, Eastern Ethiopia. The Pharma Innovation Journal. Vol. 2 No. 10, pp: 59-69.

Okan CA et al,2015. The Pull and Push Factors Influencing Choice of Place and Delivery Attendant in the Urban Slums of Nyalenda, Kisumu East District, Kenya. Department of Community Health and Development Great Lakes University of Kisumu Kenya. Faculty of Tropical Institute of Community Health and Development Great Lakes University of Kisumu. International Journal of Humanities and Social Science. Vol. 5, No. 8(1), pp. 133-40.

Parenden RD dkk, 2016. Analisis Keputusan Ibu Memilih Penolong Persalinan di Wilayah Puskesmas Kabila Bone. Artikel Penelitian Fakultas Ilmu Kesehatan Masyarakat Universitas Sam Ratulangi Manado. Hal: 36272.

Rerey HV \& Susanto N, 2012. Model Minat Ibu Memilih Tempat Bersalin Di Wilayah Kerja Puskesmas Sentani Kabupaten Jayapura. Fakultas Ilmu Kesehatan Universitas Respati Yogyakarta. Politeknik Kemenkes Jayapura. Hal: 1-10.

Risanto S, 2009. Pengaruh Persalinan Abnormal Terhadap Morbiditas dan Mortalitas Janin dan Usaha Menurunkan Kematian Perinata. Fakultas Kedokteran Universitas Gadjah Mada. Rumah Sakit Umum Pusat Dr. Sardjito Yogyakarta. Jurnal Berkala Ilmu Kedokteran Vol. 21, No. 2, hal: 12-23.

Rusnawati, 2012. Faktor-faktor yang berhubungan dengan pemilihan tempat persalinan di wilayah kerja Puskesmas Negara kec. Daha Utara kab. Hulu Sungai Selatan prov. Kalimantan Selatan tahun 2012. Jurnal Universitas Indonesia, hal: 1-6.

Yegezu RT et al, 2014. Assessment of Factors Affecting Choice of Delivery Place among
Pregnant Women in Jimma Zone, South West Ethiopia: Cross Sectional Study. College of Public Health and Medical Sciences, Department of Nursing and Midwifery. Jimma University Specialized Hospital, Jimma, Ethiopia.. Yegezu and Kitila, J Women's Health Care 2014. Vol.4, No. 1, pp. 14-25. 